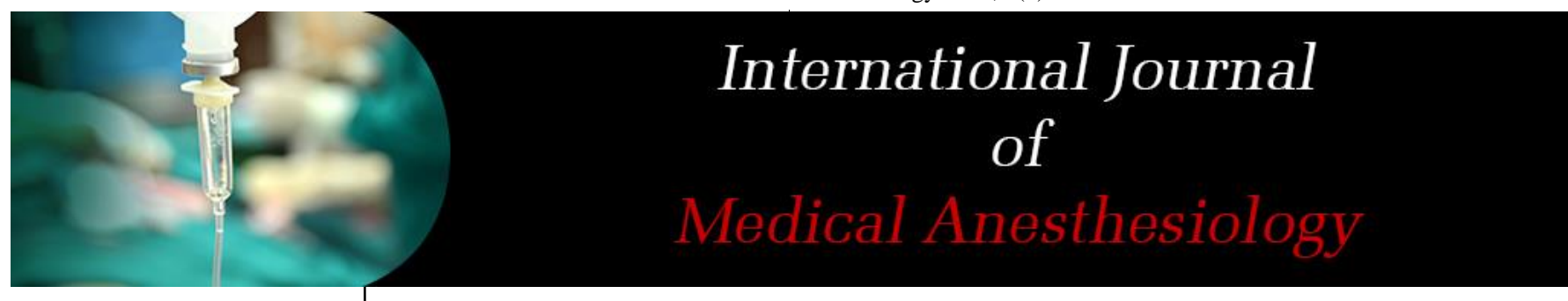

E-ISSN: 2664-3774

P-ISSN: 2664-3766 www.anesthesiologypaper.com IJMA 2019; 2(1): 15-17

Received: 14-11-2018

Accepted: 16-12-2018

Dr. D Sairamadevi MD Anesthesia, Assistant Professor, Maharajah's Institute of Medical Sciences, Andhra Pradesh, India

Dr. Yalamanchili Madhuri MD Anesthesia, Assistant Professor, Maharajah's Institute of Medical Sciences, Andhra Pradesh, India
Corresponding Author: Dr. D Sairamadevi MD Anesthesia, Assistant Professor, Maharajah's Institute of Medical Sciences, Andhra Pradesh, India

\section{A tertiary hospital based comparative study of intravenous propofol versus inhalational sevoflurane in the insertion of laryngeal mask airway in adults in rural Andhra Pradesh}

\author{
Dr. D Sairamadevi and Dr. Yalamanchili Madhuri
}

DOI: https://doi.org/10.33545/26643766.2019.v2.i2c.43

\begin{abstract}
Laryngeal Mask Airway excellent device to maintain airway in selected surgeries and obviates the need for endotracheal intubation considering the advantages of LMA over face mask and endotracheal intubation, the study had been taken up with an idea to compare the condition for LMA insertion, by most widely used intravenous inducing agent (Propofol) and volatile anaesthetic (Sevoflurane). Sevoflurane may be a useful alternative to propofol in providing anaesthesia to aid LMA insertion.
\end{abstract}

Keywords: LMA, propofol, sevoflurane, anaesthesia, vital capacity breath (VCB)

\section{Introduction}

In 1981, Dr. A.I.G.Brain ${ }^{[1]}$ designed the prototype of LMA. It is an excellent device to maintain airway in selected surgeries and obviates the need for endotracheal intubation. In year 1996, LMA was incorporated in ASA difficult airway algorithm ${ }^{[2]}$.

Other advantages of LMA, like smoother transition from anaesthesia to emergence with LMA in situ and requirement of lesser skill for insertion, has made LMA even more popular among anaesthesiologists.

Insertion of this SAD to provide and maintain a seal around the laryngeal inlet for spontaneous ventilation as well as for positive pressure ventilation, requires sufficient depth of anaesthesia and suppression of airway reflexes to avoid adverse reactions like gagging, coughing, head and limb movements etc. Considering the advantages of LMA over face mask and endotracheal intubation, the study had been taken up with an idea to compare the condition for LMA insertion, by most widely used intravenous inducing agent (Propofol) and volatile anaesthetic (Sevoflurane).

Propofol $(2.5-3 \mathrm{mg} / \mathrm{kg})$ remains the induction agent of choice for insertion of LMA as it attenuates airway reflexes more than any other inducing agent and it has also shorter elimination half-life ${ }^{[3,4]}$. On the other hand, it induces greater degree of hypotension, bradycardia, pain on injection and excitatory patient movement which is not desirable in many clinical conditions. Sevoflurane has advantages like relatively low blood-gas solubility (0.69), low pungency and minimal respiratory irritation, make it suitable inhaled induction agent for insertion of LMA. Single VCB sevoflurane has been used as an alternative to IV induction in adults. This method is rapid, with little excitatory phenomena, high patient acceptance, and good hemodynamic stability ${ }^{[5]}$. Sevoflurane is associated with delayed jaw relaxation and longer time for LMA insertion ${ }^{[6]}$.

\section{Methods}

Conducted in department of Anesthesia of Maharajah's institute of Medical Sciences between 18.5.15 - 24.06.17. After obtaining the institutional ethics committee clearance and written informed consent, 90 adult patients of ASA physical status I and II aged between 20 to 50 years, scheduled for short operative procedures under general anaesthesia were selected. Patients with h/o- difficult intubation, allergy or sensitivity to volatile anaesthetics or propofol, body wt. $>70 \mathrm{~kg}$, heavy smoker (>20 cigarettes/day), having any cardiac, renal or neurological disease, and patient's refusal were excluded from our study.

The patients were divided into two groups (Group-A and B) using a computerised random 
number table. After arrival of patients in the operation theatre, intravenous cannulation was done and all standard monitoring devices (ECG, NIBP, pulse oximetry, capnography) were attached. Each of them were preoxygenated for 3 minutes with $100 \%$ oxygen and premedicated with injection glycopyrrolate $0.2 \mathrm{mg}$ intravenously (IV), injection midazolam $1 \mathrm{mg}$ IV and injection ondansetron $4 \mathrm{mg}$ IV For group $\mathrm{A}$, a circle $\mathrm{CO}_{2}$ absorber circuit with a 3 litres reservoir bag was primed with sevoflurane $8 \%$ in a $67 \%$ nitrous oxide in oxygen at a fresh gas flow of $8 \mathrm{~L} / \mathrm{min}$ for 45 seconds (approx) ${ }^{[6,7]}$. While breathing $100 \%$ oxygen from a separate breathing system, the patients were asked to take a deep breath and exhale to tidal volume. Then the mask with the primed circuit were placed firmly over the patient's face and instructed to inhale a Vital Capacity Breath (VCB) and hold it as long as possible. If necessary a second breath had to be taken. The patients were asked to open their eyes every 3-5 seconds [6], failure to do so was taken as loss of consciousness. This was confirmed by testing the loss of eyelash reflex. The start of induction was taken as the point at which the patient completed their VCB ${ }^{[6]}$. After the loss of eyelash reflex, the ease of mouth opening was assessed (possible or impossible). If mouth opening was impossible, another attempt was made every $15 \mathrm{~s}$ up to a maximum of 3 tries. An attempt to open the mouth was considered an attempt at insertion. During this time, anaesthesia was maintained with sevoflurane at a dial concentration of $8 \%$ and nitrous oxide $67 \%$ in oxygen.

Patient in group B were induced with injection propofol 2.5 $\mathrm{mg} / \mathrm{kg}$ body weight IV premixed with $2 \mathrm{ml}$ of $1 \%$ lignocaine [6-8]. Time to loss of consciousness was calculated from the time of start of injection of propofol until loss of eyelash reflex and inability to open eyes upon verbal command ${ }^{[6]}$. After the loss of eyelash reflex, ease of mouth opening was assessed and, if possible, LMA insertion was attempted. If impossible, repeat attempts were made every $15 \mathrm{~s}$ up to a maximum of four attempts, each time preceded by propofol boluses of $0.5 \mathrm{mg} / \mathrm{kg} \mathrm{IV}{ }^{[5]}$. Incidences of hiccup, coughing, gagging laryngospasm, involuntary movement were recorded during the procedure. After insertion of LMA, anaesthesia was maintained with sevoflurane $1 \%-2 \%$ and $67 \% \mathrm{~N}_{2} \mathrm{O}$ in $\mathrm{O}_{2}$ with $8 \mathrm{~L}$ FGF.

\section{Results}

45 patients who underwent VCB induction with sevoflurane and 45 patients who underwent IV induction with propofol were similar with respect to demographic characteristics.

Table 1: Demographic data: age and body weight

\begin{tabular}{|c|c|c|}
\hline & Group A $(\mathbf{n = 4 5})$ & Group B $(\mathbf{n = 4 5})$ \\
\hline Age in years & $33.56 \pm 8.78$ & $34.06 \pm 8.47$ \\
\hline Body weight in kg & $53.46 \pm 4.74$ & $52.96 \pm 4.64$ \\
\hline
\end{tabular}

Values are mean \pm SD

Table 2: Parameter: sex

\begin{tabular}{|c|c|c|}
\hline Sex & Group A (n=45) & Group B (n=45) \\
\hline Male & $32(71.1 \%)$ & $28(62.2 \%)$ \\
\hline Female & $13(28.9 \%)$ & $17(37.8 \%)$ \\
\hline
\end{tabular}

Table 3: Characteristics of LMA insertion

\begin{tabular}{|c|c|c|}
\hline & Group A (n=45) & Group B (n=45) \\
\hline Time to loss of eyelash reflex(s) & $34.88 \pm 6.78$ & $36.48 \pm 5.66$ \\
\hline Time to jaw relaxation(s) & $101.91 \pm 22.82$ & $91.28 \pm 11.85$ \\
\hline Time to completion of successful LMA insertion(s) & $118.22 \pm 12.94$ & $115.36 \pm 20.12$ \\
\hline Successful insertion of LMA at 1 ${ }^{\text {st }}$ attempt & $40(88.9 \%)$ & $42(93.3 \%)$ \\
\hline
\end{tabular}

Values are presented as mean $\pm \mathrm{SD}$, number and (percentage)

Table 4: Mean arterial pressure and Pulse rate

\begin{tabular}{|c|c|c|c|c|}
\hline & \multicolumn{2}{|c|}{ Mean arterial pressure } & Pulse rate & \\
\cline { 2 - 5 } & Group A & Group B & Group A & Group B \\
\hline Base line & $91.86 \pm 8.86$ & $91.34 \pm 9.32$ & $92.61 \pm 14.28$ & $90.32 \pm 14.22$ \\
\hline After induction & $86.2 \pm 10.84$ & $85.32 \pm 10.48$ & $98.52 \pm 17.48$ & $92.68 \pm 14.36$ \\
\hline After LMA insertion & $83.28 \pm 12.87$ & $84.12 \pm 11.26$ & $103.98 \pm 15.24$ & $102.22 \pm 12.41$ \\
\hline
\end{tabular}

Values are number (percentage)

There was no statistically significant difference between two groups in timing of loss of eyelash reflex and LMA insertion except timing of jaw relaxation.

There was no statistically significant difference between two drugs in respect of successful LMA insertion in $1^{\text {st }}$ attempt
(Table 3 ). Values are presented as mean \pm SD.

There was no significant change in haemodynamic parameters or side effects between two groups at different time periods (Table 4 and 5).

Table 5: Incidence of complication during the procedure

\begin{tabular}{|c|c|c|}
\hline & GroupA(n=45) & Group B (n=45) \\
\hline \multicolumn{2}{|c|}{ During induction } \\
\hline Movement & 2 & 3 \\
\hline Hiccup & 0 & 0 \\
\hline Cough & 1 & 0 \\
\hline Laryngospasm & 0 & 2 \\
\hline Movement & During LMA insertion & 1 \\
\hline Hiccup & 3 & 1 \\
\hline Cough & 0 & 1 \\
\hline Gagging & 1 & \\
\hline
\end{tabular}

Values are number 


\section{Discussion}

Our study demonstrated sevoflurane VCB induction and insertion of LMA in adult compared favourably with IV propofol ${ }^{[5]}$. There was good acceptability for both groups. The time to loss of eyelash reflex was faster in group A than group B whereas that to jaw relaxation was significantly shorter in group B in our study. J. E. Hall et al., in their study comparing induction with sevoflurane $8 \%$ in $2: 1$ ratio $\mathrm{N}_{2} \mathrm{O}: \mathrm{O}_{2}$ and induction with IV propofol $3 \mathrm{mg} / \mathrm{kg}$, found time to jaw relaxation was faster in the propofol group, similar to our study but time to loss of eyelash reflex was also slightly faster in the propofol group ${ }^{[8]}$. Again, Sahar M. SiddikSayyid et al. also found significant difference between the two groups in respect to jaw relaxation, corroborating our results ${ }^{[6]}$. Priya $\mathrm{V}$ et al. in their study, comparing IV propofol with sevoflurane for insertion of LMA concluded that jaw relaxation was better with propofol resulting in better LMA.

Insertion conditions, which again was at par with our findings ${ }^{[9]}$. Similar findings were also observed in the study done by Sarkar M et al ${ }^{[13]}$.

The time to completion of successful LMA insertion was faster in the propofol group in our study which was similar to the finding of Rashdi S et al., who compared the insertion of I-gel with either sevoflurane or propofol and found that the insertion time was comparatively short with propofol ${ }^{[10]}$. Koppula RK et al., in their study comparing propofol with sevoflurane, concluded that the clinical conditions of insertion of LMA obtained with sevoflurane was comparable to that of IV propofol ${ }^{[11]}$.

Beverly K. Philip et al. in 1999 in their study concluded that sevoflurane VCI was faster than and provided patients satisfaction similar to propofol IV induction in adult ambulatory surgery. But overall incidence of induction side effects like cough and laryngospasm were higher in sevoflurane group while patients' movement was higher in propofol group. Our findings are similar to the above mentioned study ${ }^{[7]}$.

The baseline haemodynamic data (MAP and pulse rate) did not differ between two groups however the mean arterial pressure decreased and pulse rate increased during induction and LMA insertion in both the groups which was not statistically significant. These findings can be compared with the results found by Sahar M. Siddik- Sayyid et al., ${ }^{[6]}$ Hall JE et al. ${ }^{[8]}$ and Zahoor MU et al ${ }^{[12]}$ Sarkar M et al ${ }^{[13]}$. In conclusion, Sevoflurane may be a useful alternative to propofol in providing anaesthesia to aid LMA.

\section{References}

1. Brain AIG. The Laryngeal mask: a new concept in airway management. Br J Anaesth. 1983; 55:801-5.

2. Benumof J. The laryngeal mask airway and the ASA difficult airway algorithm. Anesthesiology. 1996; 84:686-9.

3. Blake DW, Dawson P, Donnan G, Bjorksten A. Propofol induction for laryngeal mask airway insertion: dose requirement and cardio respiratory effects. Anaesth Intensive Care. 1992; 20(4):479-83.

4. Scanlon P, Carey M, Power M, Kirby F. Patient response to laryngeal mask airway insertion after induction with propofol or thiopentone. Can J Anaesth. 1993; 40(9):816-8.

5. Ti LK, Chow MYH, Lee TL. Comparison of sevoflurane with propofol for laryngeal mask airway insertion in adults. Anaesth Analg. 1999; 88:908-12.

6. Siddik-Sayyed SM, Aouad MT, Taha SK, Daaboul DG, Deeb PG, Massouh FM, et al. A comparison of sevoflurane-propofol versus sevoflurane or propofol for laryngeal mask airway insertion in adults. Anaesth Analg. 2005; 100:1204-9.

7. Philip BK, Lombard LL, Roaf ER, Drager LR, Calalang I, Philip JH. Comparison of vital capacity induction with sevoflurane to intravenous induction with propofol for adult ambulatory anaesthesia. Anaesth Analg. 1999; 89:623-7.

8. Hall JE, Stewart JIM, Harmer M. Single breath inhalational induction with sevoflurane anaesthesia with and without nitrous oxide; a feasibility study in adults and comparison with an intravenous bolus of propofol. Anaesthesia. 1997; 52:410-5.

9. Priya V, Divatia JV, Dasgupta D. A comparison of propofol versus sevoflurane for laryngeal mask airway insertion. Indian J Anaesth. 2002; 46(1):31-4.

10. Rashdi S, Iftikhar N, Iqbal F, Aftab S, Khan AB. Comparison of sevoflurane and propofol for I-gel insertion. Pak J Surg. 2013; 29(1):23-5.

11. Koppula R, Shenoy A. Comparison of sevoflurane with propofol for laryngeal mask airway insertion in adults. J Anaesth Clin Pharmacol. 2005; 21(3):271-4.

12. Zahoor MU, Mansoor R, Buland K, Kazi WA, Ehsanul-Haq M. Comparison of haemodynamic changes after laryngeal mask airway insertion with propofol versus sevoflurane. Pak Armed Forces Med J. 2010; 60(3):410-4.

13. Sarkar M, Swaika S, Bisui B, Mandal MC, Sengupta S, Sheet $\mathrm{J}$, et al. A comparative study of vital capacity breath inhalation with sevoflurane versus intravenous propofol to aid laryngeal mask airway insertion in adults. Int Surg J. 2014; 1:73-6. 